\title{
Quantitative Regression Analysis of Total Hardness Related Physicochemical Parameters of Groundwater
}

\author{
Sisir Nandi*, Sharma A, Ahmed S and Teotia D \\ Department of Pharmaceutical Chemistry, Global Institute of Pharmaceutical \\ Education and Research, India
}

*Corresponding author: Sisir Nandi, Professor and Head, Department of Pharmaceutical Chemistry, Global Institute of Pharmaceutical Education and Research (GIPER), Kashipur-244713, India, Email: sisir.iicb@gmail.com ; sisirnandi739@yahoo.com

\section{Research Article \\ Volume 2 Issue 3}

Received Date: August 23, 2018

Published Date: September 12, 2018

DOI: $10.23880 /$ oajpr-16000160

\section{Abstract}

Groundwater is the major sources of water for the survival of lives. It is a gift of Mother Nature who supports water to the mankind and animals. Industrialization has been increasing day by day. This is one of the crucial factors for pointing a question mark on the quality of drinking water sourced from the underground. Industrial effluents cause pollution and imbalances in the physicochemical parameters. One of the important constituents of groundwater is total harness to which mineral content is present. It was reported that hard water contains high concentration of cations with a charge of +2 , especially $\mathrm{Ca}^{2+}$ and $\mathrm{Mg}^{2}$ and minor concentration other polyvalent ions, such as aluminium, barium, manganese, strontium and zinc. The present study is an attempt to make a quantitative correlation between the total harness and other related physicochemical parameters such as polyvalent ions. It measures the quality of buried drinking water for the household and industrial use and impacts on the public health.

Keywords: Total Hardness (T.H.); Physicochemical parameters; Quantitative regression modeling; Quality of groundwater

\section{Introduction}

Groundwater is the natural reservoir of water which is buried at the underground. It is very precious due to daily usage for humans, animals, agricultural, municipal, and industries. Because of the hidden dimension, the general public is much less familiar with groundwater compared to visible components of the water cycle, such as rain and surface water. It is the major source of drinking water in both urban and rural areas. The uncontrolled release of industrial effluents and urban wastes and the use of chemical substances in agriculture (fertilizers, herbicides, and pesticides) cause changing of physicochemical parameters related to the groundwater quality [1,2]. Solid waste from industries is being dumped near the factories and subjected to reaction with percolating rainwater and reaches the groundwater level. The percolating water picks up a large number of dissolved constituents and reaches the aquifer system and thus it contaminates the groundwater [3]. All these industries effluents contain numerous constituents like bicarbonate, chloride, sulfate, fluoride, chromium, iron, 


\section{Open Access Journal of Pharmaceutical Research}

lead, aluminium, barium, manganese, strontium, zinc and arsenic which may change the physicochemical water parameters like hardness and deteriorates the quality of groundwater in the nearby areas. Hardness is defined by water that contains an appreciable quantity of dissolved minerals (like calcium and magnesium). The insoluble precipitate is formed with soap due to the hardness of water. The hardness of water is a measure of the total concentration of the bicarbonate, chloride, and sulfates of calcium and magnesium. Water hardness is due to the presence of multivalent metal ions which come from minerals dissolved in the water $[4,5]$. Hardness is judged on the ability of these ions to react with soap to form a precipitate or soap scum. In fresh water the primary ions are calcium and magnesium; however iron and manganese may also contribute. Carbonate hardness is equal to alkalinity but a non-carbonate fraction may include nitrates and chlorides. So far as reported, hard water is not harmful to the health. It is useful to the growth of children due to the presence of calcium. It causes adheres to surfaces of tubes, sinks, dish washer and may stain clothing. Scales formed mainly due to carbonate hardness act as insulations and causes enormous loss of fuel in the boiler. Soft water is treated water in which the only ion is sodium may be harmful. Absolutely soft waters are corrosive and dissolve the metals. More cases of cardio vascular diseases are reported in case of soft water areas [6]. There were a lot experimental investigation but hardly find any theoretical quantitative regression analysis of hardness related physicochemical parameters of groundwater. Therefore, in the present effort, physicochemical parameters of groundwater like total hardness, $\mathrm{pH}$, bicarbonate, chloride, sulfate, fluoride, chromium, iron and lead were studied theoretically.

\section{Materials and Methods}

\section{Collection of Data of Water Sample}

Unnao district of Uttar Pradesh in India is famous for the tanning industry which produces leather. Leather industry effluents were being thrown into the ponds and rivers which may give negative impact to the quality of groundwater in the vicinity. It is established that a single tannery can cause the pollution of groundwater around the radius of $7-8 \mathrm{~km}$. The deterioration in chemical physical and biological properties of water is brought about by human activities [7,8]. In an attempt, Sinha and co-workers analyzed physicochemical parameters of 12 water samples collected from the wells and hand pumps in the different parts of Unnao District. In the present study, physicochemical parameters data (Table 1) were collected from the published literature [9].

\begin{tabular}{|c|c|c|c|c|c|c|c|c|c|c|}
\hline \begin{tabular}{|c|} 
Sample \\
No.
\end{tabular} & pH & $\mathrm{HCO}_{3}-\mathrm{mg} / \mathrm{l}$ & $\mathrm{Cl}^{-} \mathrm{mg} / \mathrm{l}$ & $\mathrm{SO}_{4}{ }^{2-} \mathrm{mg} / \mathrm{l}$ & $\begin{array}{c}F^{2-} \\
\mathrm{mg} / \mathrm{l} \\
\end{array}$ & $\begin{array}{c}\text { Chromium } \\
\mathrm{mg} / \mathrm{l}\end{array}$ & Iron mg/l & Lead mg/l & T.H. mg/l & $\begin{array}{c}-\log \text { (T.H.) } \\
\text { mg/l }\end{array}$ \\
\hline AS1 & 6.87 & 542.9 & 24 & 29 & 1.81 & 0.03 & 1.03 & 0.03 & 295 & -2.469 \\
\hline AS2 & 7.1 & 542.2 & 107 & 70 & 1.41 & 0.03 & 0.48 & 0.02 & 190 & -2.278 \\
\hline AS3 & 6.7 & 475.8 & 127 & 147 & 1.03 & 0.08 & 0.3 & 0.03 & 355 & -2.55 \\
\hline AS4 & 7.2 & 475.5 & 77 & 147 & 0.46 & 0.04 & 0.37 & 0.05 & 355 & -2.55 \\
\hline AS5 & 6.9 & 396.5 & 121 & 129 & 0.36 & 0.05 & 0.49 & 0.04 & 198 & -2.296 \\
\hline AS6 & 7.3 & 475.2 & 184 & 20 & 1.03 & 0.07 & 0.62 & 0.05 & 247 & -2.392 \\
\hline AS7 & 7.4 & 396.8 & 57 & 132 & 0.39 & 0.04 & 0.85 & 0.02 & 263 & -2.419 \\
\hline AS8 & 6.8 & 231.8 & 96 & 98 & 2.03 & 0.09 & 1.05 & 0.01 & 339 & -2.53 \\
\hline AS9 & 6.6 & 317.2 & 162 & 158 & 1.36 & 0.06 & 0.61 & 0.03 & 276 & -2.44 \\
\hline AS10 & 6.8 & 286.7 & 205 & 170 & 0.62 & 0.03 & 0.77 & 0.04 & 370 & -2.568 \\
\hline AS11 & 6.8 & 231.8 & 210 & 105 & 1.31 & 0.05 & 0.73 & 0.01 & 199 & -2.298 \\
\hline AS12 & 7.2 & 213.5 & 198 & 162 & 1.61 & 0.07 & 1 & 0.01 & 305 & -2.484 \\
\hline
\end{tabular}

Table 1: Physicochemical parameters of groundwater of Unnao District, Uttar Pradesh studied by Sinha et al. [9]. T.H. $=$ Total Hardness

\section{Statistical Analysis}

Simple linear regression is the method of making corelation between dependent variable, denoted $Y$, and independent variable $\mathrm{X}$. The regression model is
$\mathrm{Y}=\mathrm{a}+\mathrm{bX}$

Multiple linear regressions (MLR) is the extension of simple regression where two or more independent 


\section{Open Access Journal of Pharmaceutical Research}

variables are quantitatively correlated with the dependent variable as like

$$
Y=a+b_{1} X_{1}+b_{2} X_{2}+b_{3} X_{3}+b_{4} X_{4}
$$

Where $X_{1}$ is the first independent variable and $b_{1}$ is the regression coefficient associated with it, $X_{2}$ is the second independent variable and $b_{2}$ is the regression coefficient associated with it, and so on. This arithmetic equation is called a linear combination; thus, the response variable $Y$ can be expressed as a (linear) combination of the explanatory variables [10]. The MLR has been using for the quantitative relationships between structureactivity and property-property relationship studies. In the present study, the negative logarithm of T.H. was taken as independent variables whereas different physicochemical parameters were treated as predictors for the modeling of quantitative correlations utilizing multiple linear regressions.

\section{Results and Discussion}

Based on the above points, total hardness (T.H.) of water can be quantitatively correlated with some parameters like $\mathrm{pH}$, bicarbonate, chloride, sulfate, fluoride, chromium, iron and lead. It was well reported that the primary ions responsible for total hardness are bicarbonate, chloride, and sulfates of calcium and magnesium. Our aim is to check whether T.H. is dependent on other physicochemical parameters apart from bicarbonate, chloride, and sulfates of calcium and magnesium.

Minitab 17 software [11] was used to develop the model using multiple linear regression (MLR) statistical analyses. The regression equation is given below.

$-\log$ (Т.H.) $=-1.39-(0.006) \mathrm{PH}-(0.00051) \mathrm{HCO}_{3}{ }^{-}+$ $(0.0011) \mathrm{Cl}^{-}-(0.0022) \mathrm{SO}_{4}^{2-}-(0.090) \mathrm{F}^{2-}-(1.960)$ Chromium - (0.309) Iron - (5.380) Lead

$\mathrm{N}=12, \mathrm{R}^{2}=0.724, \mathrm{~S}=0.105$

Where $\mathrm{N}$ is a number of sample observations, $\mathrm{R}$ is the square root of multiple R-square for regression, $\mathrm{R}^{2}=1-\left[\sum\right.$ $\left.\left(\mathrm{Y}_{\text {obs }}-\mathrm{Y}_{\text {calc }}\right)^{2} / \sum\left(\mathrm{Y}_{\mathrm{obs}}-\overline{\mathrm{Y}}\right)^{2}\right]$ and $\mathrm{S}$ is the standard error of estimation. $Y_{o b s}, Y_{\text {calc }}$ and $\bar{Y}$ denote observed, calculated and mean of T.H. values, respectively.

The physicochemical parameter-based regression model can explain only $72.4 \%$ of the variances of the studied water sample data considering total hardness as response. The result is satisfactory as obtained by the $\mathrm{R}^{2}$ value of 0.724 . Therefore, the data set has been studied for further statistical validation by calculating normal probability distribution of the residuals (Figure 1). It was observed that all the data points are close to the regression line.

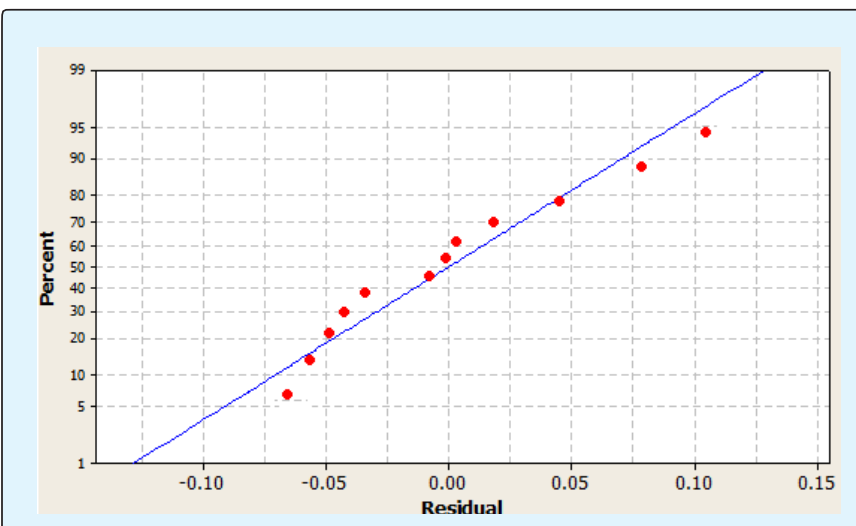

Figure 1: Normal probability distribution of the residuals.

Another important statistical metric is the T-value associated with the regression equation, defined as the modelled parameter coefficient divided by its standard error $[12,13]$. Physicochemical parameters with large $|\mathrm{T}|$ values are important in the predictive model and, as such, can be examined in order to gain some understanding of the nature of property of interest (Table 2).

\begin{tabular}{|c|c|c|c|}
\hline Parameters & Coefficient & SE of Coefficient & $|\mathbf{T}|$ \\
\hline $\mathrm{PH}$ & -0.006 & 0.174 & 0.04 \\
\hline $\mathrm{HCO3-}$ & $-5.00 \mathrm{E}-04$ & 0.0008 & 0.58 \\
\hline $\mathrm{Cl}-$ & 0.001 & 0.0009 & 1.11 \\
\hline $\mathrm{SO}_{4} 2-$ & -0.002 & 0.0011 & 2 \\
\hline $\mathrm{F} 2-$ & -0.091 & 0.129 & 0.7 \\
\hline Chromium & -1.962 & 2.192 & 1 \\
\hline Iron & -0.309 & 0.299 & 1.03 \\
\hline Lead & -5.376 & 3.798 & 1.42 \\
\hline
\end{tabular}

Table 2: |T|-values of the modelled parameters.

From the statistical analyses, it has found that $|\mathrm{T}|$ values of cations such as iron, lead and chromium are higher whereas other parameter such as anions including $\mathrm{SO}_{4}{ }^{2-}$ and $\mathrm{Cl}^{-}$produce higher $|\mathrm{T}|$ values of 2.00 and 1.11 . Anions such as $\mathrm{F}^{2}$ - and $\mathrm{HCO}_{3}$ - have intermediate $|\mathrm{T}|$ values of 0.70 and 0.58 respectively. It was well known that water contains chlorides or sulphates of calcium or magnesium or of both produce permanent hard water. 


\section{Open Access Journal of Pharmaceutical Research}

Presence bicarbonate of calcium and magnesium or of both is called temporary hard water. From the above model, it was predicted that fluoride anion is also responsible for the hardness of water, it may produce hydrogen bonding. It was postulated that presence of iron, lead and chromium are responsible for the total hardness of the groundwater. Further, it was confirmed by the experimental analyses.

\section{Experimental Validation}

To prepare hard water solutions of the corresponding iron and lead, $2 \mathrm{gm}$ of ferrous sulphate and lead acetate were dissolved in $40 \mathrm{ml}$ of distilled water in separate beakers $(100 \mathrm{ml}) .10 \mathrm{ml}$ of aqueous soap solution was added into each and shaken well by using a glass rod. Foam was not produced but precipitation or flocculation was observed (Figures 2A-B). Chemically, soap is sodium stearate. On reaction with soap, ferrous sulphate produced ferrous stearate whereas lead acetate produced lead stearate. Ferrous stearate is formed as yellowish brown precipitation and lead stearate form white flocculation.

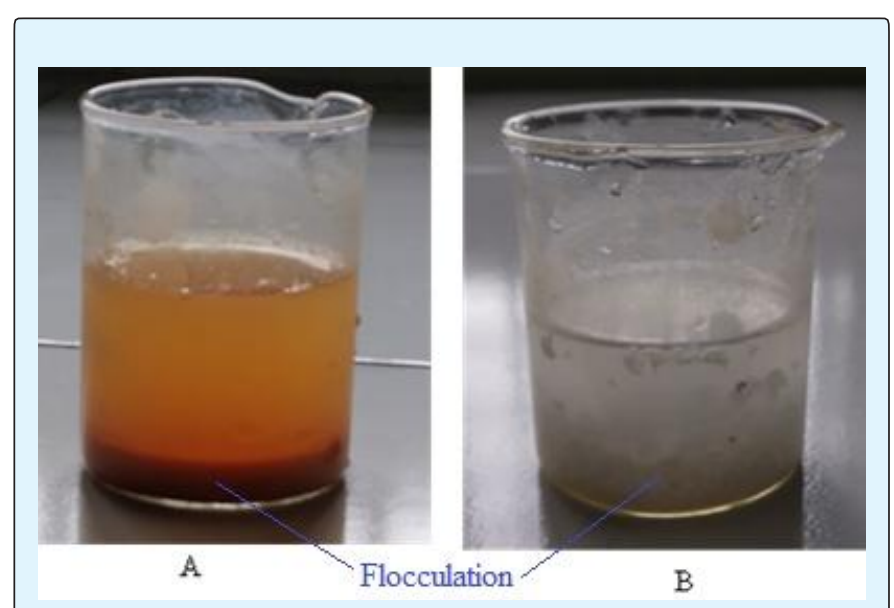

Figure 2: Flocculation produced by ferrous sulphate (A) and lead acetate (B) on addition of soap.

$2 \mathrm{gm}$ potassium dichromate was dissolved in $40 \mathrm{ml}$ of distilled water. $10 \mathrm{ml}$ of concentrated sulphuric acid was added. On heating with concentrated acid, oxygen was evolved and chromium sulphate along with potassium sulphate was obtained.

$2 \mathrm{~K}_{2} \mathrm{Cr}_{2} \mathrm{O}_{7}+8 \mathrm{H}_{2} \mathrm{SO}_{4} \rightarrow 2 \mathrm{~K}_{2} \mathrm{SO}_{4}+2 \mathrm{Cr}_{2}\left(\mathrm{SO}_{4}\right)_{3}+8 \mathrm{H}_{2} \mathrm{O}+3 \mathrm{O}_{2}$

Sisir Nandi, et al. Quantitative Regression Analysis of Total Hardness Related Physicochemical Parameters of Groundwater. Pharm Res 2018, 2(3): 000160.
To it, $10 \mathrm{ml}$ of soap solution was added. Flocculation was produced due to formation of chromium stearate (Figures 3A-B).

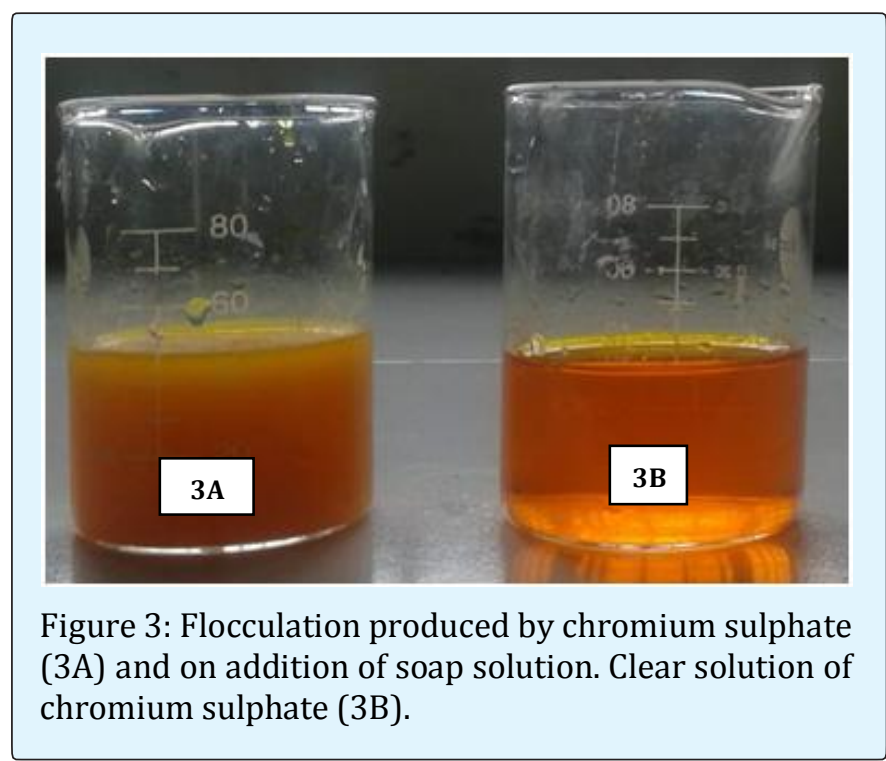

Acknowledgements: Authors acknowledge "Water for Welfare: An Uttarakhand Initiative" (WFW-UI) a Virtual Centre of Excellence, IIT Roorkee for the research grant.

\section{Conflict of interest: None}

\section{Conclusion}

In this theoretical study, a quantitative regression model was developed by correlating negative logarithm of total hardness with the other physicochemical parameters like $\mathrm{pH}$, bicarbonate, chloride, sulfate, fluoride, chromium, iron and lead to check whether T.H. is influenced by any of these physicochemical properties of the groundwater. From the above Table 2, it is cleared that T-values of $\mathrm{Cl}^{-}, \mathrm{SO}_{4}{ }^{2-}$, lead, iron and chromium are higher than other parameters. Therefore, it may be concluded that the total hardness does depend not only on chloride and sulfates of calcium and magnesium but also other significant physicochemical parameters such as lead, iron and chromium that may govern the total hardness of the groundwater. Further, it was experimentally validated by obtaining flocculation produced by the solutions of ferrous sulphate, lead acetate and chromium sulphate on addition of aqueous soap solution. 


\section{Open Access Journal of Pharmaceutical Research}

\section{References}

1. Pandey SK, Tiwari S (2008) Physicochemical analysis of groundwater of selected area of Ghazipur city-A case study. Nature \& Science 7(1): 17-20.

2. Saravanakumar K, Kumar RR (2011) Analysis of water quality parameters of groundwater near Ambattur Industrial Area, Tamil Nadu, India. Indian J Sci Technol 4(5): 560-562.

3. Yadav KK, Gupta N, Kumar V, Arya S, Singh D (2012) Physico-chemical analysis of selected ground water samples of Agra city, India. Recent Research in Science Technology 4(11): 51-54.

4. Gupta DP, Sunita, Saharan JP (2009 Physicochemical analysis of ground water of selected areas of Kaithal city (Haryana). Researcher 1(2): 1-5.

5. Kethikeyani TP, Velavan TP, Ramesh M (2002) Physico-chemical and biological characteristics of river Shanmuganadhi, Tamil Nadu. Env Eco 20: 482486.

6. Durlach J, Bara M, Guiet-Bara A (1989) Magnesium level in drinking water: its importance in cardiovascular risk". In Itokawa Y, Durlach J (Eds.), Magnesium in health and disease. J Libbey, London pp: 173-182.
7. Rathore J ( 2011) Assessment of water quality of River Bandi affected by textile dyeing and printing effluents, Pali, Western Rajasthan, India. International J Environ Sci 2(2): 572-580.

8. Sinha S, Agarwal N, Pandey S, Grover V (2016) Impact of tanneries on ground water contamination in Unnao district. Green Chemistry \& Technology Letters 2(2): 110-114.

9. Yan X (2009) Linear Regression Analysis: Theory and Computing. World Scientific, Pp: 1-2.

10. Draper NR, Smith H (1998) Applied Regression Analysis $3^{\text {rd }}$ (Edn.), John Wiley.

11. Minitab 17 Statistical Software (2010) [Computer software]. State College, PA: Minitab, Inc.

12. Bagchi MC, Mills D, Basak SC (2007) Quantitative structure-activity relationship (QSAR) studies of quinolone antibacterials against $M$. fortuitum and M. smegmatis using theoretical molecular descriptors. J Mol Model 13(1): 111-120.

13. Nandi S, Bagchi MC (2009) QSAR of aminopyrido[2,3d]pyrimidin-7-yl derivatives: anticancer drug design by computed descriptors. J Enzyme Inhib Med Chem 24(4): 937-948. 